\title{
Fat Tail Analysis on S\&P 100 Stocks-before and after US President Election
}

\author{
Sandeep Kumar Thakur*
}

\begin{abstract}
The main aim of this paper is to determine whether the volatility in the stocks can be created by events like the US Election and whether it leads to Fat Tail in the stocks. Fat Tail analysis is a key factor in determining volatility and has been used in the economy as well as in many other fields like climate and health. Log return has been used to determine the Fat Tail. To make the work more reliable, two Presidential election periods, that of Barack Obama and Donald Trump is selected and is compared for volatility and Fat Tail. For this study, stocks from the S\&P 100 are selected and observed. The results show that the US economy is not at all driven by who comes in power and when but rather by the present economic condition. Stocks showing heavy tails during the Obama presidency are primarily because the economy was under Sub Prime Crisis too.
\end{abstract}

Keywords: Fat-Tail, Volatility, S\&P 100, Gaussian Distribution, US Election, Barack Obama, Donald Trump

\section{Introduction}

The United States plays a major role in the world. From the Tech Bubble Bust to highly inflated housing prices before the Global Financial crisis, it has changed the volatility rate in stock price. Investors' perceptions, both institutional and retail are driven by a

\footnotetext{
* Risk Analyst, Ernst \& Young - Global Delivery Services, India; sandeep10.386kumar@gmail.com
} 
lot of factors. Many stock prices went too high and fell in a day or two to its lowest in years creating unusual Fat Tails.

A Fat Tail is a property of probability distributions that exhibit extremely large kurtosis, especially with the ubiquitous normal distribution that is an example of a thin tail distribution itself. In academic terms, leptokurtosis is called the condition of distribution of probability that exhibits Fat Tail(s). A Fat-Tail risk in financial markets refers to significant market swings that cannot be forecasted based on the normal distribution of the probability of return alone (Cook Pine Capital LLC, 2008). The effective calculation of volatility requires not only the mean and variance analysis but also sufficient detection of the conditional distribution, Fat Tails, and price spikes. The study of the fat tail can also provide many facts about the data set. It can specify the type of distribution the data has (kurtosis) and whether the data has long-tail or heavy tail.

Long Tail: A long-tail distribution has tails that gradually taper off rather than sharply drop off. In simple terms, if the data points for most of the observations are distributed far from the mean point, such type of distribution is said to have a long tail distribution. They are a subset of heavy-tailed distributions. Visualising the idea of a long-tailed function is easy while making it concrete is slightly harder (Whitt \& Feldman, 1998).

Heavy Tail: This type of distribution has a tail that is thicker than linear distribution (Bryson, 1974). In other words, a thin tailed distribution goes to zero, slower than one with weak tails. Under the curve of the probability distribution function, there will be more mass. There are many outliers with very high values of heavy-tailed distributions. The longer the tail, the greater the likelihood that a sample would contain one or more excessive values.

Fat Tails are also very significant when it comes to specific events prevailing in the economy. The unpredictable event can create a heavy weighted fat tail and a stable Gaussian distribution can be seen when the market is in favour of the event that is happening in the economy. 
One such unpredictable event is the US President Election. It is usually a highly anticipated time for most companies and investors as a new government can bring up new reforms which in turn make their investments sling. During 2008, Barack Hussein Obama II ran for US President. He graduated from Harvard Law School, where he was Harvard Law Review's first African American representative and then returned to help the community in Chicago, Illinois. The closure of local steel plants hurt some of the communities, so Barack helped them rebuild their buildings and other structures (Washington et al., 2017). He worked as a civil rights lawyer in Chicago after assisting the communities in Chicago. He later taught at the Law School at the University of Chicago, helping students acquire more expertise. He ran for the House of Representatives of the United States in 2000 but lost. He was always against going to war in Iraq and at a protest in October 2002, he spoke against it. He ran and won for the U.S. Senate in 2004. He became even more popular when he spoke on behalf of John Kerry at the 2004 Democratic National Convention. Barack stood against John McCain for president in 2008 (Elkatawneh, 2016).

He won 28 out of 50 states, receiving more than 66 million votes to 58 million from John McCain. On Tuesday, November 4, 2008, the first African American President was elected. The time was very critical as economies across the globe were hit by the housing crisis and companies stock went south. But Obama made many reforms to make sure that things get back on track. (Ramadhani, 2014) During Obama's precedence, the stability in the market was unpredictable and that is under study in this paper.

Donald John Trump portrayed a completely different picture from what the former did. Trump was a real estate developer and businessman who operated, controlled, or leased his name to several world hotels, casinos, golf courses, resorts, and residential properties. Trump has also given his name to dozens of retail companies since the 1980 's- including licensed brands of clothes, cologne, food, and furniture- and Trump University, which conducted real-estate preparation seminars from 2005 to 2010 (Immelman \& Ph, 2019). His private conglomerate, the Trump Organisation, comprised some 500 businesses in the early 21st 
century, including hotels and resorts, residential properties, merchandise, and entertainment and television.

Trump announced in June 2015 that he would be a candidate for the 2016 U.S. Presidential Election (Lynch, 2017). Pledging to "make America great again," Trump vowed to generate millions of new workers; sanction American companies who shipped jobs overseas; dismantle Obama's biggest policy victory, the ACA and many more (Wickett, 2017).

\section{Literature Review}

Distribution is an accurate instrument characterising the excellent danger and chance inherent in fat-tailed information. Crashes or booms on the equity market are extreme realisations of the fundamental distribution of returns. EVT (Extreme Value Theory) frames the issue of extreme occurrences elegantly in the context of restricting sample maxima and minima distributions. (Lebaron \& Samanta, 2004) Significant uncertainty about the value of the tailindex is often unavoidable when insurance claims are governed by fat-tailed distributions. Applied to claims resulting from general distributions of Pareto, the resulting premium is shown to be the proportion of the two biggest anticipated claims, for which the proportion of the real claims is both an unbiased and consistent estimator (Calculation \& Risk, 2005). Recent empirical results indicate that macro-economic factors are rarely distributable. For instance, with Laplace Fat Tails, the distributions of aggregate production growth-rate time series in many OECD countries are well approximated by symmetric exponential-power (EP) densities. In this work, we evaluate whether the Real Business Cycle (RBC) and standard New Keynesian (NK) medium-scale models are capable of replicating this statistic regularity. We simulate both models drawing shocks distributed between Gaussian and Laplace and investigate the statistical characteristics of simulated time series. The findings cast doubts on whether the model's RBC and NK can provide a satisfactory representation (Ascari, Fagiolo, \& Roventini, 2012).

In many modelling methods, normal distributions are frequently used to define reality, but in many instances, truth follows a fat- 
tailed distribution that is not ordinary. This critical hypothesis leads to possibly incorrect models, particularly when modelling extreme occurrences such as danger or shifts in the financial market. (Beleidy, 2014) Recent events in the economic and insurance industries and the looming difficulties of a changing global climate point to the need to rethink how we measure and handle disastrous and dependent hazards. Management can be just as useful as our measuring instruments (Crime \& America, 2005).

The latest financial crisis has underscored the significance of modelling and handling extreme risk, particularly savings on pension. However, virtually all conventional models of ideal stockbond distribution suppose that the risk is normally distributed (bell-shaped). Inventory market risk exhibits "Fat Tails". Allowing for "Fat Tails" can add significant computational complexity to the already quite complicated conventional optimisation structure. It is widely known that financial asset returns distributions show fatter tails compared to normal distribution. It means that when $\mathrm{VaR}$ is calculated with the expectation of naturally distributed returns, the downside probability of a portfolio comprising fat-tailed assets as assessed by value-at-risk is underestimated. This implies that incorrect calculations of the VaR will be given through parametric conversion for divergent condense rates as adhered to by the Basle Committee regulatory framework. It is no surprise that it was appropriate to 'ad hoc-ly' multiply the VaR by 3 to provide the Basle capital requirements with a bigger, more representative number (Huisman, Pownall, \& Koedijk, 1998). In the case of ReHFT, financial Reynolds figures were significantly higher, culminating in a more reliable positive tail exponent or a. The detection points for standard Re were significantly lower relative to ReHFT. It implies a significant difference in the exponent to tailor the magnitude of $a$. This novel insight parallels research on Indian indexes in the past (Pan \& Sinha, 2008). Nonetheless, this study focussed on the log-returns produced from index observations, and compared to the current research it would be distinctly different.

The complementary study on Financial Reynolds number, a proxy for stock market volatility, has been found to follow the same pattern as well (asymptotic decay) (Ghosh \& Krishna, 2019). Similar studies also reflect undue bubble and unexplained random 
volatility either led by herd or by some unknown parameter sputtering unnecessary volatility finally leading to a crash point (Ghosh, B., \& Kozarević, 2019; Ghosh, B., Krishna, Rao, Kozarević, \& Pandey, 2018; B. Ghosh, 2017).

The emerging capital market is highly volatile and hard to predict. Financial investors' behaviour is significantly influenced by the instability in emerging capital markets of trading mechanisms. Despite being an increasingly attractive financial environment, developing markets are exposed to diversified risks and structural deficiencies. Consequently, for optimal portfolio selection and risk management strategies, financial econometric analysis and its degree of accuracy have a major significance. Therefore, when measuring the importance of the fat-tailed distribution concept, certain aspects should be considered to ensure that the consequences are significant- risk management, portfolio selection of financial assets, valuation of derivatives, and financial hedging respectively. In other terms, mispricing and unsatisfactory hedging require an inadequate layout of the underlying asset. On the other hand, to predict rare events, the latest global financial crisis exposed the serious need to model and handle extreme risk. (Birău, 2013)

\section{Data Set}

The data set in this paper is for S\&P 100 stocks and is from two different timelines, i.e. one when Obama was elected as the President and another when Trump was elected as the President. The exact timestamp for the data set is from 02nd September 2008 to 30th January 2009 for Obama Presidency and from 1st September 2016 to 30th January 2017 for Trump.

\section{Methodology and Interpretation}

The analysis of the fat tail in this paper is done in a simple way using an excel sheet by calculating the return for the period on all S\&P 100 stocks and converting those returns to a percentage. Thereafter, the data is sorted out in decreasing order. The bracket for the normal tail is between $+5 \%$ and $-5 \%$; beyond that, all the data set are considered as a part of the tail. The positive tail for the 
data set consists of return value more than $+5 \%$ and is counted as Right/Positive Tail. Similarly, the negative tail is obtained by data points having to return more than $-5 \%$ and are counted as Left/Negative Tail. The Total Tail weight is calculated by the sum of both positive and negative tail and the ratio of this with respect to the total observations for a particular stock gives the percentage tail weight.

This process is repeated for all the S\&P 100 stocks for both the time stamp, i.e. election for both Presidents.

\begin{tabular}{|c|c|c|c|}
\hline Company Name & $\begin{array}{c}\text { Company } \\
\text { Code }\end{array}$ & $\begin{array}{c}\text { Tail \% } \\
\text { During } \\
\text { Obama } \\
\text { President } \\
\text { Election } \\
\text { Period }\end{array}$ & $\begin{array}{c}\text { Tail \% } \\
\text { During } \\
\text { Trump } \\
\text { President } \\
\text { Election } \\
\text { Period }\end{array}$ \\
\hline Bank Of America & BAC & 57 & 2 \\
\hline 3m Company & MMM & 8 & 0 \\
\hline Abbott Laboratories & ABT & 4 & 0 \\
\hline Accenture & $\mathrm{ACN}$ & 15 & 1 \\
\hline American International Group & AIG & 57 & 0 \\
\hline Allergan Plc & AGN & 12 & 2 \\
\hline Altria Group & $\mathrm{MO}$ & 9 & 0 \\
\hline Bank Of New York Mellon & BK & 42 & 0 \\
\hline Berkshire Hathway B & BRK-B & 15 & 0 \\
\hline Boeing Co & BA & 22 & 0 \\
\hline Bristol-Myers Squibb Company & BMY & 12 & 6 \\
\hline Caterpillar Inc & CAT & 25 & 1 \\
\hline Citigroup Inc & $\mathrm{C}$ & 59 & 0 \\
\hline Coca-Cola Company & $\mathrm{KO}$ & 8 & 0 \\
\hline Colgate Palmolive & CL & 10 & 1 \\
\hline Danaher Corporation & DHR & 14 & 0 \\
\hline Duke Energy Corporation & DUK & 12 & 0 \\
\hline Dupont Inc & DD & 26 & 0 \\
\hline Eli Lilly And Company & LLY & 18 & 3 \\
\hline Emerson Electric Company & EMR & 24 & 0 \\
\hline Exelon Corporation & EXC & 26 & 0 \\
\hline Exxon Mobil Corp & XOM & 19 & 0 \\
\hline Fedex Corporation & FDX & 22 & 1 \\
\hline Ford Motor Company & $\mathrm{F}$ & 41 & 0 \\
\hline General Dynamics Corporation & GD & 14 & 1 \\
\hline General Electric Company & GE & 37 & 0 \\
\hline Goldman Sachs Group Inc & GS & 42 & 1 \\
\hline Home Depot Inc & $\mathrm{HD}$ & 21 & 0 \\
\hline
\end{tabular}




\begin{tabular}{|c|c|c|c|}
\hline Honeywell International Inc & $\mathrm{HON}$ & 21 & 1 \\
\hline International Business Machines & IBM & 13 & 0 \\
\hline Jhonson \& Jhonson & JNJ & 7 & 0 \\
\hline Jpmorgan Chase \& Co & JPM & 51 & 0 \\
\hline Lockheed Martin Corporation & LMT & 14 & 2 \\
\hline Lowe's Companies Inc & LOW & 28 & 1 \\
\hline Mastercard Inc & MA & 34 & 0 \\
\hline Merck \& Company Inc & MRK & 18 & 1 \\
\hline Metlife Inc & MET & 50 & 2 \\
\hline Morgan Stanley & MS & 56 & 1 \\
\hline Nike Inc & NKE & 18 & 0 \\
\hline Occidental Petroleum Corporation & OXY & 37 & 2 \\
\hline Pepsico Inc & PEP & 8 & 0 \\
\hline Pfizer Inc & PFE & 13 & 1 \\
\hline Philip Morris International Inc & PM & 15 & 0 \\
\hline Procter \& Gamble Company & PG & 9 & 0 \\
\hline Schlumberger Nv & SLB & 38 & 1 \\
\hline Simon Property Group Inc & SPG & 54 & 0 \\
\hline Southern Company & $\mathrm{SO}$ & 7 & 0 \\
\hline Target Corporation & TGT & 31 & 2 \\
\hline Union Pacific Corporation & UNP & 30 & 1 \\
\hline United Parcel Services Inc & UPS & 13 & 0 \\
\hline United Technologies Corporation & UTX & 16 & 0 \\
\hline Unitedhealth Group Incorporated & UNH & 31 & 0 \\
\hline Verizon Communications Inc & $\mathrm{VZ}$ & 15 & 0 \\
\hline Visa Inc Class A & $\mathrm{V}$ & 25 & 0 \\
\hline Walgreens Boots Alliance Inc & WBA & 14 & 0 \\
\hline Walmart Inc & WMT & 9 & 0 \\
\hline Walt Disney Company & DIS & 23 & 0 \\
\hline
\end{tabular}

\section{Conclusion}

Volatility in stocks is very common as each investor perceives differently thereby having different strategies. But these volatilities also have a limit and often they cross the limit depending on the situation prevailing in the market. Fat Tails in stocks can be directly linked to the magnitude of movement- more the movement, heavier or longer will be the tails. Considering the US Election as one such event in any country's economy, the stocks of S\&P 100 are observed. Two different periods, i.e. Obama in power and Trump in power are taken both before and after. After analysing all the stocks for both periods it is evident that events like elections have very little gauge when it comes to developed countries. Most of the 
stocks which are showing very heavy tail (like, AIG, CITI, GM, and so on) are all in the period when Obama was elected as the US President but it cannot be linked to that event as during the same timestamp Sub-Prime Crisis had already encompassed many companies and few countries. To make the work more reliable when the same process is applied to the other period, i.e., when Trump was elected as the President, very few stocks, show a heavy tail indicating the fact that events like presidency election does not have a short term effect on volatility and in turn does not create Fat Tails.

There might be a significant effect of the election of a new government in the stocks of developing countries and therefore can be taken up for further research.

\section{References}

Ascari, G., Fagiolo, G., \& Roventini, A. (2015). Fat-tail distributions and business-cycle models. Macroeconomic Dynamics, 19(2), 465-476.

Beleidy, S. El, Bommareddy, S., Narapareddy, S., \& Yoner, N. (2014). Applications of fat tail models to financial markets proposal. Unpublished Project Report, 1(1), 1-19. George Mason University.

Birău, F. R. (2013). Analyzing fat-tailed distributions in emerging capital markets. Cks Bucuresti, 3, 1026-1032.

Cook Pine Capital LLC. (2008). Study of Fat-tail risk. Cook Pine Capital LLC., 1-11.

Crime, T., \& America, L. (2005). The unholy trinity: Transnational. Resources for the Future, XI(2), 33.

Elkatawneh, H. H. (2016). Bridging theory and practice leadership/Barack Obama. SSRN Electronic Journal, (January 2016). https:// doi.org/ 10.2139/ ssrn.2867772

Gay, R. (2005). Premium calculation for fat-tailed risk. ASTIN Bulletin: The Journal of the IAA, 35(1), 163-188.

Ghosh, B., \& Kozarević, E. (2019). Multifractal analysis of volatility for detection of herding and bubble: evidence from CNX Nifty HFT. Investment Management \& Financial Innovations, 16(3), 182-193.

Ghosh, B., Krishna, M., Rao, S., Kozarević, E., \& Pandey, R. K. (2018). Predictability and herding of bourse volatility: An econophysics analogue. Investment Management and Financial Innovations, 15(2), 317326.

Ghosh, B. (2017). FRA-CDS-VDAX based credit crash model: A German conundrum. International Journal of Economic Research, 14(8), 221-228. 
Ghosh, Bikramaditya, \& Krishna, M. C. (2019). Power law in tails of bourse volatility - Evidence from India. Investment Management and Financial Innovations, 16(1), 291-298.

Huisman, R., Pownall, R., \& Koedijk, K. (1998). VaR-x: Fat tails in financial risk management. The Journal of Risk, 1(1), 47-61.

Immelman, A. (2017). The Leadership Style of U. S. President Donald J . Trump. Management Consultants and Their Leadership Style: A Contingency Perspective, 1-6.

Lebaron, B., \& Samanta, R. (2005). Extreme value theory and fat tails in equity markets. SSRN Electronic Journal, 1(November 2005), 32.

Lynch, T. (2017). President Donald Trump: A case study of spectacular power. Political Quarterly, 88(4), 612-621.

Pan, R. K., \& Sinha, S. (2008). Inverse-Cubic Law of index fluctuation distribution in Indian markets. Physica A: Statistical Mechanics and Its Applications, 387(8-9), 2055-2065. https://doi. org/10.1016/ j.physa. 2007.11.031".

Ramadhani, F. S. Z. A. (2014). The Leadership of Barack Obama (p. 6). Retrieved from https:// www.researchgate.net/ publication/ 333485726_THE_LEADERSHIP_OF_BARACK_OBAMA

Washington, G., Adams, J., Jefferson, T., Madison, J., Monroe, J., Adams, J. Q., Bush, G. W. (2017). Barack Obama Barack Obama.

Whitt, A., \& Feldman, A. (1998). Fitting mixtures of exponentials to longtail distributions to analyze network performance models. Performance Evaluation, 31(3-4), 245-279.

Wickett, X. (Ed). (2017). America's international role under Donald Trump. Royal Institute of International Affairs, (X), 8-12. 